\title{
Architecture and digital drawing tablets, bringing back human control over HAL
}

\section{Gaia Leandri}

Departamento de Expresión Gráfica Arquitectónica, Universitat Politècnica de València, Spain, Dipartimento di Neuroscienze, Riabilitazione, Oftalmologia, Genetica e Scienze Materno Infantili (DINOGMI), Università degli Studi di Genova, Italy.

\begin{abstract}
Architectural imagery and design are nowadays pervaded by computerization, consequently freehand drawing suffered a drastic decline. This paper reviews the advantages and drawbacks of digitalization, examines the reasons of the reborn need for freehand drawing and reports about published evidence of creativity being facilitated by hand movement. A new drawing medium is now available in the form of digital tablets. These allow freehand drawing with more ease and efficiency than on paper but hand movements and feeling are the same as in traditional drawing. Aim of this paper is to provide the basis for a proposal to merge advantages of digitalization with creativity stemming from freehand drawing by the use of modern digital drawing tablets in architecture. The preliminary results of a pilot survey carried out in 8 countries revealed that there is a widespread need for architectural academic courses of freehand drawing on digital tablets, so far not implemented. It is expected that the survey may be completed in the next few months and a wider sample may provide more detailed indications. In conclusion it is proposed that the digital tablets may be the future solution for a fruitful union between the digital and the creative imagery in architecture.
\end{abstract}

Keywords: Digital tablet; drawing; architecture; freehand; creativity; education. 


\section{Introduction}

Digitally driven processes are currently used in architectural design and widely taught as a must in the educational path of new architects. Matter of fact it would be unrealistic not to use Computer Aided Design (CAD) in a modern studio. But with development of hardware and software architects and especially students are increasingly depending more and more on computers. In Stanley Kubrick's 2001: A Space Odyssey, the supercomputer HAL had full command of the spaceship, and was granted full trust to the point that the crew had a passive role, until HAL turned against them (Williams, 1984). Advantages and drawbacks of computerization in architecture are now being debated, and after decades of unmingled enthusiasm, doubts about complete computer trust are arising. A balance in the architect's practice and, above all, in the educational curriculum should be reached so that HAL can be of help, but the crew should be well in command. This paper discusses the issue, and proposes solutions stemming from new technologies.

\section{Background}

Drawing plays an essential role in architecture, either as planning or representation of an already made building. One of the first testimonials of the imperative need to draw in order to design and communicate architecture is given by a graffiti dating back to the Ggantija phase in Maltese prehistory $(3600-3200$ BC), found at the Hagar Qim site (Amazing architecture in Prehistoric Malta - National Museum of Archaeology, Malta). Until about fifty years ago, the technique of transferring ideas or perceived images to a flat surface, be it stone, clay, papyrus, parchment or paper, had changed little. The hand, guided by the cerebral cortical activity where ideas are formulated or perception elaborated, traced signs which materialized what was an ephemeral inner process of neurological activity and fixed it for an indefinite time on a medium. The resulting craft was to be read by others, but also meant for the author himself to store in a safe memory his mental work, to be retrieved and thought over. Since the mid-1960s development of computers brought the possibility of drawing by inputting XY coordinates; for the first time drawing was not a mind-hand-paper (draw) process, but a mind-computer-paper (print). That meant that the author's craft was processed and stored as bits of electronic states and not accessible any more to the human sight if not by the help of the computer itself. That also meant that difficult engineering calculations could be performed in an eyeblink and with the highest precision. But the link of mind to hand was replaced by the relation of mind to computer. It was all very well for the boring complex calculations, which, in pre-computer era were considered the hardest hindrance to the architect's project. But the core of architecture are art, intuition, fantasy, production of novel and useful ideas, in a word: creativity (Amabile and Pratt, 2016). Computer aided design has now reached goals of unheard sophistication, it is widely taught in universities, it is a tool so essential that no architect could dare to think not to use it in a project. On the 
other hand, progress in computer graphics has also meant that photographic quality images could be produced depicting virtual buildings and environments, still "in nuce", as if they were already built objects. Photographic renders are another must of the current architectural profession. In both cases (CADs and photographic renders), once data are input into the computer, the operator loses most of the control. He/she must abide to constraints dictated by hardware and software, often by restricting the range of project ideas in order to feed the computer with something that the machine can handle. This way, the computer/software combination dictates the project, but it is quite the opposite of a creative, divergent thinking, it is a bottleneck. Why should an architect choose to squeeze his brain activity through such a bottleneck? At university courses he/she has been taught how to use CADs and virtual reality, or simulation, software. The architect has learned to appreciate speed, ease of use, precision, stunning special effects. A wide straight road which compels addiction (Guney, 2015), numbing the mind into a simple. So creativity is sacrificed to smoothness and ease of mind. Such attitude of passiveness to computers is something that should raise concern as it will grow in relevance paralleling the evolution in processors and software. The dualism between "poetic" and "functional" drawings (Meisenheimer, 1987) should be overcome in the name of creativity and efficiency.

\section{Current state of the art}

We are now in an age of simulation, where widespread and cheap computational power creates illusions for our sight, hearing, touch and motion. The architectural world is particularly prone to succumb to such technological drive, mainly under the request of the public. What are the consequences of this whirl of simulations? They are discussed in a fairly recent book: "The death of drawing: architecture in the age of simulation" (Scheer, 2014). The book is centred upon the issue of the present shift from representation to simulation in architecture.

\subsection{Representation}

Representation is the craft produced by a human being who acts upon a medium as to reproduce his/her ideas borne from perception of the outside world (reality). Examples in figurative art are a drawing or a sculpture. However, the perception of the crafter is not perfect and the true external reality cannot be known (a common trend of philosophy since Plato). Besides, according to individual senses and brain processing (perception), the reality can be perceived in different ways by different individuals, so the resulting representation through craft (i.e. the drawing) will always be approximate and recognized to be so by any beholder. Of course, the representation could be of ideas and not linked to current reality, but always stemming from previous similar experience of perception. Ambiguity is an inherent property of representation and it "provides rich opportunities for creative expression” (Scheer, 2014). 
The creative process is linked to investigation and choices carried out by the crafter about the reality to be represented.

\subsection{Simulation}

Simulation is "an artificial environment that creates an artificial experience that is felt to be reality" (Scheer, 2014). Simulation at every level, spanning from movies, television, computer games, theme leisure parks is ever pleasing because it resembles reality but it is not reality; it is a human creation where everything is known and under control. Everything can be done but on condition that it stays within the constraints of the provided frame, be it software, hardware or, as in theme parks, buildings. It is a limited cosmos where nothing is ambiguous. The limits are set by the authors of simulation, so no user can develop ideas outside the work of imagination performed by others. In architecture digitally made 3D renderings of photographic quality are extremely popular and easy to make. With virtual reality software even their internal spaces can be visited in detail. These are the "blue skyed..lush leafed..populated by groomed and grinning clip-art figures..postcards from the future" originated by "Cartesian given" projects (Jacob, 2017). Most architects praise such products of simulation even on grounds of creativity. By providing flexibility in scenery, many solutions can be tested, precision granted, nice images produced by any architect capable of handling the software, apparently difficult projects are within the grasp of students (Ivarsson, 2010; Khan, 2018; Lawson, 1994). On the other hand there is now a widespread consensus about the limits of CADs and computational architecture, which ought be used with caution not to hamper freedom of thought and not to give way to "fake" creativity (Bernath, 2007; Lawson, 2002) .

\subsection{Beholder and student preferences on architectural imagery}

Architectural 3D renders are simulations of something not built yet, very appealing, but usually they do not display any artistic touch more than a postcard. When architects, professionals in the building trade and City councilors were asked to give opinions on one side about photographic renders or montage (i.e. simulations), and on the other side on watercolours and perspective drawings (i.e. representations), it turned out that all three groups judged the computer generated simulations as more realistic and accurate than hand made representations, whilst the latter were more "abstract" or conceptualized (BatesBrkljac, 2009). Such results are something that was to be expected; of course a glossy photograph is more realistic and accurate than a hand drawing, but is that more convincing, emotionally moving or useful as an architectural representation? It depends on the onlooker and on the message that the author of the drawing wants to transmit. The photograph, or its $3 \mathrm{D}$ twin, is something aseptic, coldly objective, which does not convey the creative impulse of the crafter. Simulations are said to be something handy to explore the mood of the public concerning projects to be. For this purpose, visual preference surveys (VPS) are commonly 
used. They avoid "the vexing problem of dealing with the slippery notion of esthetic value per se by replacing it with a poll of personal reactions whose results can be handled with familiar statistical techniques. This substitution equates the complex notion of esthetic value with the operational one of visual pleasure" (Scheer, 2014). Further on, the same author states that "the very decision to base design on this criterion already denies design any other purpose than providing a pleasing environment, creating an experience with no questioning of content" (Scheer, 2014). In conclusion, simulations, although useful to practical ends, should be regarded as what they are and reactions to them evaluated carefully. Investigations about student preferences between hand made representations and CAD simulations are perhaps simpler to explore. Summing up the results of a series of surveys (Basa and Şenyapih, 2005; Hanna and Barber, 2001; Islamoglu and Deger, 2015; Ivarsson, 2010; Şenyapili and Basa, 2006), it is possible to conclude that students adopt a fairly pragmatical approach in general, by adapting themselves and their design to the tools provided (Ivarsson, 2010), they acknowledge that computer drawing requires less effort, saves time and is more practical (Şenyapili and Basa, 2006). In the first years of the course computer drawing is less preferred because students have not enough practice yet, so they prefer hand drawing (Islamoglu and Deger, 2015); however, preferences by computer experienced students were split in two halves between hand and computer drawings, and the majority of them considered hand drawing as better expressing their personality (Şenyapili and Basa, 2006).

\subsection{Bodily involvement and related physiology}

Hand made crafts are a reflection of the author's personality as much as a signature, making onlookers tune up in syntony. From this point of view hand made representations are much more catching for the public than simulations. But it is mainly in the making of a craft that a big difference takes place. The extremely complex movements needed for hand drawing are not only the result of efferent motor activity by the central nervous system, they are also the source of perception. This is an inward bound afferent activity, also called proprioception, that starting from receptors of joints and muscles goes back to the brain to control the execution of the primeval orders (Kandel et al., 2013), but also to stimulate new ideas for new movements. In the process of architectural design, such bodily involvement is supposedly of extreme importance as it should be at the basis of the mental process of divergent thinking and creativity (Guilford, 1956). There is now some evidence that parts of the central nervous system related to movement and proprioception might be linked to creativity (Heilman et al., 2003). Certainly there are many data now available leading to conceive the importance of body activity and senses in the conceptual architect's work on one side, whilst pointing towards a sort of intellectual flatness and levelling effect by the use of computer (Mallgrave, 2011). 


\section{Desiderata and possible solution: the digital freehand}

There is little doubt that drawing by pen and paper in many instances is a slow and sometimes painstaking process. Second thoughts and errors require delicate erasure and remaking. On the other hand, the rewards of freehand drawing are reviving this form of expression, as highlighted in the previous chapters. It should now be possible to reconcile the need of efficiency with creative drawing by exploiting recent progress in hardware and software technology. The sentence: "We need to change how we think about drawing, moving beyond outdated notions of "hand graphics" and "rendering" to encourage a less rigid and more accessible style of freehand sketching that supports and energizes our best digital technologies." (Richards, 2013) well expresses such current spirit. Digital freehand is now feasible by the use of digital drawing tablets and software for raster and vectorial graphics. Both items have undergone great improvements in the last years. By far the most important innovation has been the screen drawing tablet, where you can draw directly on a screen, with available sizes from few inches up to an impressive 32". Leaving out the largest sizes, their price is now affordable to any professional or student. The goal is that you should be able to paint and draw on it as if using a pen or a brush. Pens for tablets are now wireless and even battery free, as they are powered by electromagnetic induction by the tablet itself. They are pressure and tilt sensitive. Their dimension and grip are the same as the real thing. There is a wide range of sophisticated software of any price, and even for free. With the right software you can have a whole range of drawing tools, of different shapes, which combined with the sensitive pen, mimic the behaviour of the actual device. Erasing and changing your mind is now extremely easy and fast, so you can sketch and experiment styles or new solutions at will. This freedom is actually expected to increase occurrence of creative thought, as there is no restraint deriving from the effort of redoing an already finished craft.

\section{A pilot survey on digital freehand drawing}

The architectural academic world seems not to have widely adopted or encouraged the freehand drawing on digital tablets, so the author launched two pilot surveys by email, one addressed to teachers and one to students. By design, the surveys were not limited to a given university or school, as there would have been a strong sampling location bias. The involved countries were Canada, France, Germany, Italy, Spain, Switzerland, United Kingdom and United States of America. The surveys have been launched recently and they are far from complete. Some provisional results are reported hereafter. The teacher survey addressed the following items: 1) which tools do you currently use for free hand drawing architecture, 2) does your School/Institute/University run a course on architectural free hand drawing with digital tablets, 3) does your School/Institute/University run a course on rendering techniques for 3D models, 4) do you think it would be useful to institute a course on digital techniques for architectural imagery production, 5) do you own or have access to a digital graphic tablet. 
Eleven teachers responded so far to the questionnaire, $100 \%$ use pen or pencil and paper, $18 \%$ use watercolor and $63 \%$ use digital drawing tablets, just $18 \%$ of their institutions run a course on freehand drawing with digital tablets, but all institutions run a course on $3 \mathrm{D}$ rendering, and all of them think it would be useful to run a course on digital techniques for architectural imagery. Also, all of them have access to a digital drawing tablet. The student survey had these items: 1) educational level, 2) which tools do you currently use for free hand drawing architecture, 3) does your University run a course on architectural free hand drawing with digital tablets (no CAD), 4) does your University run a course on rendering techniques for 3D models, 5) would you like to attend a course on digital techniques for architectural imagery production, 6) do you own or have access to a digital graphic tablet. Eighteen students answered so far, of these $50 \%$ were postgraduate, $44 \%$ undergraduate and $5 \%$ from a technical school. $77 \%$ use digital tablets, $72 \%$ pen or ink and $83 \%$ pencil and paper. About $20 \%$ of their institutions run a course on freehand drawing on digital tablets and $90 \%$ were interested in attending a course on digital techniques for architectural imagery. Only $60 \%$ have access to digital tablets.

Aim of the survey is to assess how widespread is the use of digital tablets in the academic world and how much teachers and students draw freehand on them. In the next months it is expected that at least a total of 50 teachers and 100 students should answer the questionnaire so that it should be understandable how such usage is distributed. From the scanty data currently, available it is evident that freehand drawing on tablets is still in little use in the academia, which was something predictable by the rarity of paper or web reports on this issue.

\section{Conclusions}

The space odyssey ends with a message of hope, humanity is reborn to a new life after HAL has been killed and the new hope is humbly communion with Deity (Williams, 1984). In the metaphor all advantages of the mighty computer had turned out in a selfish rebellion that had decreed its death. It may be guessed that excess of computerization could be the executioner of creative architecture. But something is astir and the feeling that poetics should be given way to regain control over plain coordinates is surfacing now. Architects are now realizing that they don't think with numbers only but first they have to think with the creative part of the brain, the bodily brain. Drawing, easy and free, onto new medium, the digital canvas, will preserve and provide new spirituality to architecture. 


\section{References}

Amabile, T.M., Pratt M.G. (2016). The dynamic componential model of creativity and innovation in organizations: Making progress, making meaning. Research in Organizational Behavior, 36: 157-83.

Amazing architecture in Prehistoric Malta - National Museum of Archaeology, Malta. Amazing Architecture in Prehistoric Malta. https://artsandculture.google.com/culturalinstitute/beta/exhibit/\%C2\%A0amazingarchitecture-in-prehistoric-malta/zAJCNDmJOFfQKA.

Basa. I., Şenyapih, B. (2005) The (in) secure position of the design jury towards computer generated presentations. Design Studies, 26: 257-70.

Bates-Brkljac, N. (2009). Assessing perceived credibility of traditional and computer generated architectural representations. Design Studies, 30: 415-37.

Bernath, D. (2007). The intrusive rendering: dictation of stereotypes and the extra-ordinary. Taiwan in Comparative Perspective, 1:37-69.

Guilford, J.P. (1956). The Structure of Intellect. Psychological Bulletin, 53:267-93.

Guney, D. (2015). The Importance of Computer-aided Courses in Architectural Education. Procedia - Social and Behavioral Sciences, 176: 757-65.

Hanna, R., Barber, T. (2001). An inquiry into computers in design: attitudes before-attitudes after. Design Studies, 22:255-81.

Heilman, K.M., Nadeau, S.E., Beversdorf, D.O. (2003). Creative Innovation: Possible Brain Mechanisms. Neurocase: The Neural Basis of Cognition, 9: 369-79.

Islamoglu, O.S., Deger, K.O. (2015). The Location of Computer Aided Drawing and Hand Drawing on Design and Presentation in the Interior Design Education. Procedia - Social and Behavioral Sciences, 182: 607-12

Ivarsson J. (2010). Developing the construction sight: Architectural education and technological change. Visual Communication, 9: 171-91.

Jacob, S. (2017). Architecture enters the age of post-digital drawing. Metropolis. https://www.metropolismag.com/architecture/architecture-enters-age-post-digitaldrawing/.

Kandel, E.R., Schwartz, J.H., Jessell, T., Siegelbaum, S.A., Hudspeth, A.J., Mack. S., editors. (2013). Principles of neural science. Fifth edition. New York Lisbon London: McGrawHill Medical.

Khan, M.R. (2018). Role of Computers Technology: Architectural Design. IJRASET 6: 2936-42.

Lawson, B. (2002). CAD and Creativity: Does the Computer Really Help? Leonardo 35: $327-31$.

Lawson B. (1994). Design in mind. Oxford [England]; Boston: Butterworth Architecture.

Mallgrave, H.F. (2011). The architect's brain: neuroscience, creativity, and architecture. Pbk. ed. Chichester, West Sussex, U.K. ; Malden, MA: Wiley-Blackwell.

Meisenheimer, W. (1987). The functional and the poetic drawing. Daidalos: Berlin Architectural Journal 25: 111-20. 
Richards, J. (2013). Freehand Drawing and Discovery. Urban sketching and concept drawing for designers. Hoboken, New Jersey: Wiley \& Sons.

Scheer, D.R. (2014). The death of drawing: architecture in the age of simulation. London; New York: Routledge.

Şenyapili, B., Basa, Ý. (2006). The Shifting Tides of Academe: Oscillation between Hand and Computer in Architectural Education. Int J Technol Des Educ, 16: 273-83.

Williams, D.E. (1984). 2001: A space odyssey: A warning before its time. Critical Studies in Mass Communication 1: 311-22. 